\title{
AOR
}

Selected Papers of \#AoIR2020:

The $21^{\text {st }}$ Annual Conference of the

Association of Internet Researchers

Virtual Event / 27-31 October 2020

\section{TWITTERING RESEARCH, CALLING OUT AND CANCELING CULTURES: A STORY AND SOME QUESTIONS}

\author{
Suzanne de Castell \\ The University of British Columbia \\ Helen W. Kennedy \\ The University of Nottingham \\ Sarah Atkinson \\ King's College London \\ Jennifer Jenson \\ The University of British Columbia \\ Colleen Thumlert \\ University of Toronto
}

\section{Background and Context}

This is an analysis of how Twitter played a significant, agentive and accountable role in the difficult birth and premature unravelling of a government-funded international feminist research network. We situate this case study and this process of initiation and annihilation within the broader context within which social media platforms are a critical site of intensive affective discursive practices through which individual and institutional reputations are made and unmade - frequently with far reaching professional and or personal consequences.

To date there has been little academic study of the broader implications of both the potential benefits of social media for academic networking (see Stewart, B. (2016) for an ethnographically grounded analysis of the benefits) and the perils (Basak, R., Ganguly, N., Sural, S., \& Ghosh, S. K., 2016). One of the only explicit publications on this topic is the very recent book by Diane Anderson (2018) Problematic: How Toxic Callout Culture Is Destroying Feminism. 
Through this case study, we look at the ways in which social media such as Twitter can provide feminist academics with very public, very visible evidence of the issues they are aiming to counter which can then be pivotal in gaining funding and/or approval for publication. A prominent example of this is the way in which \#Gamergate brought to international popular and public attention the misogyny that feminist game studies had been decrying for years. Suddenly, this was no longer a minoritarian feminist research finding but a very real public outpouring of toxic, virulent misogyny on a mass scale.

\section{Funding Feminism: Gamergate's Unwitting Gift?}

In a social networking world, we can be sure that \#Gamergate's furious explosion of online misogyny in 2014, at least in part, fueled the project's funding success. Gamergate highlighted an increasingly violent public voice threatening, quite literally, violence against women speaking in or on videogames, imparting a topical urgency to the already serious problems we were addressing, and making our proposal for a cross-sectoral interventionist partnership more compelling. Then, as now, using the term "feminist" was considered a self-destructive move (Lopez, Muldoon, McKeown, 2019), but since we only wanted to, or indeed could, do the work in those terms, to be consistent and honest with our research we chose to persist with it, and were surprised and gratified to find the program funded to the tune of millions of research dollars. The Gamergate hashtag and its wide circulation via Twitter had provided a high profile platform through which feminist research was legitimated.

This case study involves the comparative analysis of two data sets - the first - detailed written responses of the research project participants gathered in a workshop at the concluding event of the funded project, and the second - a set of tweets and responses that erupted over a number of days shortly after that event. A study of how internet communications impacted the life and somewhat premature death of a research network was undertaken for two reasons. The first is that the quality of the data provided through the rapidly disseminated and amplified negative 'shaming' tweets might be able to speak clearly and persuasively about how Twitter works, especially as a medium for research communication. We captured a data set small enough, deep enough, and focused enough to be an exemplary testing ground to investigate the causal impacts of Twitter's algorithmic ethics on the transformation of information, ideas, and professional and personal reputations. The second is that just five days before, we had materially gathered in-depth qualitative feedback on the value and efficacy of the project with nearly 40 people. We had used an innovative reflexive tool to gather this feedback and thus had a second rich and comprehensive data set that told a very different but much less visible narrative about the project.

The data produced through the materially embodied event had a much slower gestation, as it needed to be transcribed and coded and then analysed through standard academic processes. As such, this rich, complex, embodied and reflexive data remains invisible and is not easily subject to the rapid dissemination and upvoting of discursive practices within Twitter and other social media platforms. For this presentation, we subject these two data sets, their origins, their processes of dissemination and their sentiment to a deep, dispassionate feminist analysis seeking to understand how we might ensure that material lived realities are not effaced through virtual discursive practices that damage bodies and reputations without consequence. 


\section{Conclusion}

A noteworthy feature of this research network was the high number of professional and personal relationships that pre-existed the project, hence both online and offline data sets include prior friends, collaborators, and co-workers, as well as staff and students. What made this project distinctive, and especially promising, is that the bonds between and among partners weren't just forged for this particular grant, but in the majority of cases had years of collaborative work and scholarly association behind them-and those that were newly forged shared explicit commitments to feminist research and praxis. Relationships in this network weren't simply academic or intellectual or disciplinary or, when payment was involved, not only financial - but, in a good sense, "ideological", that is to say, explicitly principled. In addition to this shared commitment to feminist principles, practices, and aspirations, there were multiple kinds and degrees of relationships.

Taken together, these two discrete sets of data powerfully demonstrate the capability of Twitter as a platform whose design enables it to shape user behaviours, and more specifically, to destabilize and indeed dissolve, instantaneously and without accountability, not just embodied professional and personal relationships (Ross, 2019), but important trajectories of scholarly and engaged research - and not just conceptions, but practices of truth. What happens when an information economy supersedes and overrides what occurs in 'real life'? This opportunistic, illuminating look into the impact of a small, localized Twitter event on a network of researchers demonstrates, yet again, the tensions, ruptures, and conflict addressed and provoked by feminist work.

\section{References}

Anderson, D. E. (2018). Problematic: How toxic callout culture is destroying feminism. Omaha, Nebraska: University of Nebraska Press.

Basak, R., Ganguly, N., Sural, S., \& Ghosh, S. K. (2016, April). Look before you shame: A study on shaming activities on Twitter. In Proceedings of the 25th international conference companion on world wide web (pp. 11-12).

Lamba, H., Malik, M. M., \& Pfeffer, J. (2015, August). A tempest in a teacup? analyzing firestorms on twitter. In 2015 IEEE/ACM International conference on advances in social networks analysis and mining (ASONAM) (pp. 17-24). IEEE.

Lopez, K. J., Muldoon, M. L., \& McKeown, J. K. L. (2019). One day of \#Feminism: Twitter as a complex digital arena for wielding, shielding, and trolling talk on Feminism. Leisure sciences, 41(3), 203-220. DOI: 10.1080/01490400.2018.1448022

Ross, L. (2019, August 17). I'm a black feminist. I think call-out culture is toxic. The New York Times. https://www.nytimes.com/2019/08/17/opinion/sunday/cancel-culture-callout.html

Stewart, B. (2016). Collapsed publics: Orality, literacy, and vulnerability in academic Twitter. Journal of applied social theory, 1(1), 61-86. 
Wright, L., Ruths, D., Dillon, K. P., Saleem, H. M., \& Benesch, S. (2017, August). Vectors for counterspeech on Twitter. In Proceedings of the first workshop on abusive language online (pp. 57-62). 